\title{
Fasciae anatomy
}

\author{
Carla Stecco $\cdot$ Fabrice Duparc
}

Published online: 15 November 2011

(C) Springer-Verlag 2011

\section{Keywords Fasciae Fascia $\cdot$ Anatomy}

Within the last two decades, the fasciae and their properties have gained central importance to clinicians practicing in various conventional and alternative therapies and the fascial tissue is actually the subject of a wide range of scientific research with many specializations. The results from the worldwide research activities constitute a body of significant and important data, but this clinical interest is not supported by in-depth anatomical studies. Indeed for many years the fasciae have been considered by the anatomists only as a "white envelope for the muscles", and very little attention has been given to their macroscopic and histological anatomy. In anatomic displays the fascia is generally removed, so the viewer can see the organs, nerves and vessels but fails to appreciate the fascia which connects, and separates, these structures. It is probably for this reason that different descriptions of the fasciae exist in the literature and various terms are presently used to define the same structure. Furthermore, often in the same textbook, the same terminology can be used with clearly different meanings. As anatomists, clinical anatomists and clinicians, we have clearly often forgotten the "envelop" that surrounds the tissues and organs we study, teach and describe, or care. Regarding the number of articles published in Surgical and Radiologic Anatomy during the last decade, only 14 titles contained the term "fascia" [1-14]. Researching through the keywords, it is more frequent but not constant even a fascial structure is studied in the article.

C. Stecco · F. Duparc $(\bowtie)$

Laboratory of Anatomy, Faculty of Medicine,

Rouen University, Rouen, France

e-mail: fabrice.duparc@univ-rouen.fr
The aim of this issue of Surgical and Radiological Anatomy especially devoted to the topic "fasciae" is to find some answers to several rather specific questions concerning fascial anatomy:

- Deep muscular fascia is a dense, regular connective tissue similar to an aponeurosis, as suggested by some authors, or it is an irregular loose connective tissue?

- Inside the deep fasciae can we recognize different regular sublayers, or are the fasciae composed of intertwined bundles of collagen fibers?

- How are the deep fasciae related with the underlying muscles?

- Does the superficial fascia exist? Does it have a specific structure, or not?

- How do the various fasciae appear under ultrasound, MRI, and CAT scans? Could these instruments help us to understand the structure of the fasciae in living people? And what about the relationship between fasciae and surrounding structures?

- What is the role of the extracellular matrix, and in particular of the hyaluronic acid component?

- Could fasciae be considered elastic tissue? What is the percentage of elastic fibers within fasciae? Are there regional variations?

- Are fasciae innervated? And what type of receptors could be recognized within fasciae?

- Do the fasciae possess a basal tonus? Have they the capacity to actively contract?

- Do fasciae have a role in proprioception and in peripheral motor coordination?

Answers to these questions could contribute to clinician's understanding of the biomechanical behavior of the fasciae, their role in acute and chronic myofascial pain syndromes and of the real effectiveness of different therapies. 
In this issue, three articles deal with the fasciae of the abdominal wall, of the pelvis, and one is related to the reconstruction of the thoracolumbar and crural fasciae. The medical imaging of the fascia is exposed with biomechanical consideration about the myofascial forces transmission during knee flexion and pathological conditions related to the ankle sprains. The mechanical properties of the plantar aponeurosis contribute to illustrating the role of specific thick areas of fibrous issues. The histochemistry features are studied with the hyaluronan contents and the relevance in myofascial pain. The involvement of the fasciae in canal and tunnel syndromes is presented through normal and variable anatomy of the Guyon's canal, and with an example of anatomical basis of a surgical endoscopy technique of treatment of the tarsal tunnel syndrome. The development in fetuses is evoked through an immunohistochemical study.

We hope these articles will contribute to a better knowledge of the fasciae anatomy and to future studies.

\section{References}

1. Abu-Hijleh MF, Roshier AL, Al-Shboul Q et al (2006) The membranous layer of superficial fascia: evidence for its widespread distribution in the body. Surg Radiol Anat 28(6):606-619

2. Apaydin N, Basarir K, Loukas M et al (2008) Compartmental anatomy of the superficial fibular nerve with an emphasis on fascial release operations of the leg. Surg Radiol Anat 30(1): $47-52$
3. Caggiati A (2000) Fascial relations and structure of the tributaries of the saphenous veins. Surg Radiol Anat 22(3-4):191-196

4. Cornu JN, Phe V, Fournier G et al (2010) Fascia surrounding the prostate: clinical and anatomical basis of the nerve-sparing radical prostatectomy. Surg Radiol Anat 32(7):663-667

5. Duparc F, Coquerel D, Ozeel J et al (2010) Anatomical basis of the suprascapular nerve entrapment, and clinical relevance of the supraspinatus fascia. Surg Radiol Anat 32(3):277-284

6. Gaudio E, Riva A, Franchitto A et al (2010) The fascial structures of the rectum and the "so-called mesorectum": an anatomical or a terminological controversy? Surg Radiol Anat 32(2):189-190

7. Loukas M, Shoja MM, Thurston T et al (2008) Anatomy and biomechanics of the vertebral aponeurosis part of the posterior layer of the thoracolumbar fascia. Surg Radiol Anat 30(2):125-129

8. Mauroy B, Goullet E, Stefaniak X et al (2000) Tendinous arch of the pelvic fascia: application to the technique of paravaginal colposuspension. Surg Radiol Anat 22(2):73-79

9. Hyare H, Wisco JJ, Alusi G et al (2010) The anatomy of nasopharyngeal carcinoma spread through the pharyngobasilar fascia to the trigeminal mandibular nerve on 1.5 T MRI. Surg Radiol Anat 32(10):937-944

10. Ramsaroop L, Singh B, Allopi L et al (2006) The surgical anatomy of the parotid fascia. Surg Radiol Anat 28(1):33-37

11. Stecco A, Macchi V, Masiero S et al (2009) Pectoral and femoral fasciae: common aspects and regional specializations. Surg Radiol Anat 31(1):35-42

12. Stecco C, Pavan PG, Porzionato A et al (2009) Mechanics of crural fascia: from anatomy to constitutive modelling. Surg Radiol Anat 31(7):523-529

13. Taser F, Shafiq Q, Ebraheim NA et al (2006) Enlarged perforating branch of peroneal artery and extra crural fascia in close relationship with the tibiofibular syndesmosis. Surg Radiol Anat 28(1):108-111

14. Wavreille G, Bricout J, Mouliade S et al (2010) Anatomical bases of the free posterior brachial fascial flap. Surg Radiol Anat 32(4): 393-399 